Article

\title{
Prolonged Sitting Posture: Massage and Physical Exercise Pro- gram as Effective Therapy in 45 Sedentary Officers using Their Vehicles Full Time
}

\author{
Dossou Semako Gerard*, Lawani Mohamed Mansourou, Yessoufou Lafiou, Tigri Tertulie Nawal, Houeto Vignon \\ Gratien, Lawani Mohamed Nadil Olabiss
}

How to cite this paper: Dossou, G., Mansourou, L. M., Lafiou, Y., Nawal, T. T., Gratien, H. V., \& Olabiss, L. M. N. (2021). Prolonged Sitting

Posture: Massage and Physical Exercise Program as Effective Therapy in 45 Sedentary Officers using Their Vehicles Full Time. Universal Journal of Sport Sciences, 1(1). DOI: 10.31586/ujss.2021.010101. Retrieved from https://www.scipublications.com/journal/index.php/ujss/article/view/22

Received: May 01, 2021 Accepted: June 10, 2021 Published: June 12, 2021

Copyright: (c) 2021 by the authors. Submitted for possible open access publication under the terms and conditions of the Creative Commons Attribution (CC BY) license (http://creativecommons.org/licenses /by/4.0/).
Departement of STAPS, INJEPS, University of Abomey Calavi, Porto/Novo, Benin

* Correspondence: dossousemako@gmail.com

\begin{abstract}
The high prevalence of low back pain associated with prolonged sitting as a result of work demands, is a major public health problem. Added to this is the sedentary lifestyle and full-time use of vehicles, keeping workers in this seated position. We now know the many benefits of regular exercise and physical activity. Inactivity is considered a risk factor associated with the development of lower back pain. We undertook this study to make subjects aware of the consequences of this posture. In addition, we wanted to help them relieve lower back pain and functional disability caused by prolonged sitting posture. To achieve this, we have set ourselves the goal of assessing the effect that the combination of a physical exercise program and massage with shea butter could have on lumbar pain and functional disability in inactive sedentary officials with full-time lumbar pain driving their vehicles. To achieve this goal, we brought together 45 subjects divided into three experimental groups. The results show that the group receiving the combination of an exercise and massage program with shea butter, experienced a significant decrease in pain and functional disability over the 6 weeks. Thus, the combination of an exercise and massage program with shea butter allows effective management of pain and functional disability in inactive sedentary officials.
\end{abstract}

Keywords: Exercise program, massage, shea butter, prolonged sitting posture, inactive sedentary posture

\section{Introduction}

Prolonged sitting posture contributes to many disorders, particularly in the cervical and lumbar spine [1-3]. Most authors suggest that maintaining the physiological curvature of the spine is crucial for the biomechanics of the sitting position, as well as the location of the head and the position of the pelvis [3]. Optimal professional sitting posture and sitting behavior have been widely discussed in the literature in recent years. The longheld doctrine of an ideal sitting position which is "as upright as possible" has been strongly questioned [4], and has been slowly replaced by the concept of "dynamic sitting", where sitting positions are continually changed [4]. A review of the literature conducted by Daian \& al. [5], suggests that there is no ideal sitting posture. According to these authors, regular movements and a sitting posture with preferred lumbar lordosis are essential to prevent low back pain. The modification of the sitting position can modify the geometry of the spine [6], as well as the lumbar disc pressure [1,7]. Therefore, dynamic behavior in a sitting position is able to vary the loading conditions of the vertebral segments, which induces an efficient pumping mechanism in the vertebral discs [8]. This mechanism is believed to be of critical importance for the nutrition of the intervertebral discs as well as for resistance to degenerative changes [9]. Therefore, one could conclude that office workers should travel more during their working hours. 
However, in our services and administrations in Benin, we see that employees spend almost all of their time in a seated position and only get up for rare moments of filing files. Worse, these employees permanently use vehicles for their daily trips, which increases the duration of maintaining a seated posture at home. In addition, they are sedentary subjects. And in the literature, sedentary lifestyle and prolonged sitting posture are the causes of lower back pain in men. Almost all of these employees after a few years of work complain of low back pain and some functional inability to perform tasks to which they were accustomed. To solve this public health problem in Benin, we asked ourselves whether the combination of several methods validated by the literature could they promote the relief of these employees? Thus, our objective, through this experimental study, is to show that the combination of a physical exercise program with shea butter massage, promote the effective management of lower back pain and functional disability in sedentary civil servants who spend almost all of their time in a sitting position. To achieve this goal, the following research methodology has been adopted.

\section{Methods}

\subsection{Experimental setting and type of research}

This is an experimental study that took place in the Communes of Djougou and Ouaké (Republic of Benin). The Biomechanics and Performance Laboratory of the National Institute for Youth, Physical Education and Sport (INJEPS) and the Sport-HealthService Center served as a support framework for the experiment.

\subsection{Population and sampling}

The study involved a group of 45 active, sedentary public servants with low back pain caused by prolonged sitting posture (on duty, in their vehicle and at home). They have completed at least 10 years of service. In addition, these officials are aged under 40 and not more than 45 years old. We used a non-probabilistic method. Indeed, the reasoned choice technique was used for the constitution of the sample. The choice of this technique is based on the following reasons: to eliminate confounding variables as much as possible; eliminate officials who developed lower back pain unrelated to prolonged sitting posture; eliminate those who suffered from the distal hernia, painful secondary socio-professional activities, obese and any ailments that could lead to low back pain; and retain only those who have received approval from their doctors or a health specialist.

\subsection{Criteria}

Inclusion criteria: Sedentary civil servant with 10 years living in the communes of Djougou and Ouaké; Spent most of his working time in his department chair; suffering from lower back pain caused by prolonged sitting posture; Using his vehicle full time; At least 40 years old and at most 45 years old; be authorized by a health specialist to do physical activities; give written consent

Non-inclusion criteria: Active officials; Not suffering from back pain; The origin of the back pain is not related to prolonged sitting posture; Civil servants who do not have a car and those who use their vehicle part-time; Officials with herniated discs, spinal static disorders, infection, osteoarthritis, arthritis, osteoporosis, fractures, kidney stones, and even pancreatitis.

Exclusion criteria: Civil servants under medication and analgesia; Officials who successively missed three sessions of the training program; Those with diagnosed high blood pressure; And those who refused to continue experimenting.

\subsection{Data collection equipment and technique}

For the data collection in the field, we used the following equipment: A questionnaire adapted to collect the anthropometric data of the subjects, socio-professional activities and on the antecedents of pain contracted before the function; Stopwatches to evaluate the duration of the adoption of the sitting posture during the day in all our subjects; A record 
of the progress of pain (given by EVA) at each start of the 10 sessions of the program; A French version of the functional incapacity scale for the evaluation of low back pain (EIFEL) questionnaire; a Hana brand bathroom scale with a max capacity of $150 \mathrm{~kg}$ and an accuracy of $0.1 \%$. was used to assess the body mass of subjects; a measuring rod graduated from 0 to $200 \mathrm{~cm}$ made it possible to measure the size of the subjects to the nearest millimeter; a stopwatch for recording the durations of the work sequences; a rating of the level of pain by a visual analogue scale. The EVA being a ruler with a slider placed between "no pain" and "maximum pain"; graduated from zero to one hundred millimeters.

\subsection{Experimental protocol}

\subsubsection{Experimental plan}

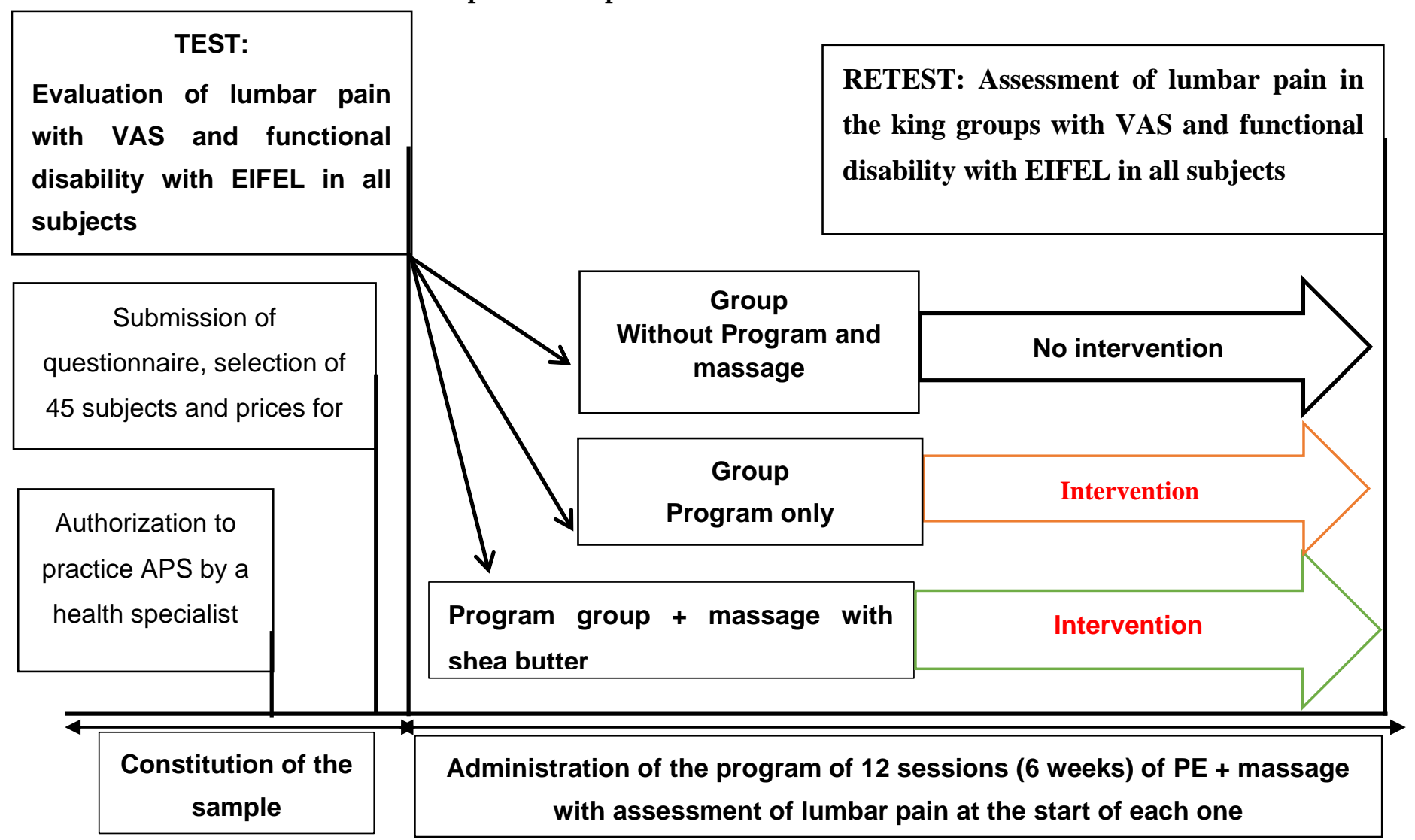

Figure 1. Experimental design

\subsection{Data collection strategies}

This study brought together 45 officials suffering from low back pain. These officials were approached in their departments and in their homes for the constitution of the study sample. Officials who met the inclusion criteria, and who gave their written consent, were instructed on the subject of the study.

1. Weight gain: When the digits 0.0 appear, the subject takes off his shoes and points to the scale to be weighed (standing in the middle of the scale with feet slightly apart and without moving). Three measurements are taken and the average of the three gives the subject's weight. All weight gain is done by the experimenter.

2. Waist measurement: the subject is standing on the base of the measuring board with the feet slightly apart. The back of his head, shoulder blades, buttocks, calves and heels should all touch the vertical board. The subject's head is held so that the horizontal line from the ear canal to the lower edge of the eye socket is parallel to the base of the board. 
3. Assessment of pain: It was assessed at the start and at the end of the experiment. In addition, it was evaluated at the start of each session at the level of the experimental group in order to follow the progression of the pain. For the measurement, the subjects move the cursor on a ruler graduated from 0 to 10 depending on the intensity of pain.

4. Assessment of the subject's functional disability: At the beginning and at the end of the experiment, all subjects from both groups complete the functional disability scale questionnaire for the assessment of low back pain (EIFEL).

\subsection{Variables studied}

Independent variables: Body mass index, $\mathrm{BMI}=\mathrm{MC} / \mathrm{T} 2$ (in $\mathrm{kg} / \mathrm{m} 2$ ); age (years); back pain exercise program and massage with shea butter.

Variable dependent: Intensity of lower back pain; Functional limitation.

\subsection{Ethical considerations}

At the start of this study, we required and obtained the authorization of the health specialist in charge of the subject's medical follow-up. After sensitizing the subjects on the objectives and interests of the study, informed written consent was obtained from each subject to express their agreement to participate.

\subsection{Statistical analysis}

The collected data were compiled and then analyzed using IBM SPSS version 21 software. This allowed us to perform the descriptive analysis of the variables studied. We performed non-parametric tests. Wilcoxon's rank test was adopted for comparing variables within a group at the start and end of the study. The significance level was set at $p$ $<0.05$.

\section{Results}

\subsection{General presentation of the study sample}

This study was carried out on 45 sedentary male civil servants spending almost all of their time in a seated position. Table 1 shows the characteristics of the three study groups. The average age of the subjects in our sample is 43.23 years \pm 1.12 . The average weight is $86.41 \mathrm{Kg} \pm 1.32$ and the average height is $1.87 \mathrm{~cm} \pm 0.06$. The average BMI is estimated at $23.37 \mathrm{~kg} / \mathrm{m} 2$.

Table 1. characteristics of the study subjects

\begin{tabular}{|c|c|c|c|}
\hline & $\begin{array}{l}\text { Experimental } \\
\text { group II }\end{array}$ & Experimental group I & $\begin{array}{l}\text { A group of wit- } \\
\text { nesses }\end{array}$ \\
\hline Age (average in years) & $43,54 \pm 1,32$ & $43,27 \pm 1,00$ & $44,38 \pm 1,26$ \\
\hline Weight (average in $\mathrm{Kg}$ ) & $79,85 \pm 1,43$ & $82,45 \pm 1,08$ & $78,5 \pm 1,14$ \\
\hline Size (average in centimeter) & $185 \pm 5,5$ & $188 \pm 4,60$ & $183 \pm 5,22$ \\
\hline Body mass index (BMI) (kg / m2) & 23,33 & 23,32 & 23,44 \\
\hline $\begin{array}{l}\text { Feeling of low back pain due to } \\
\text { prolonged sitting }\end{array}$ & $100 \%$ & $100 \%$ & $100 \%$ \\
\hline Professional activities & \multicolumn{3}{|c|}{$\begin{array}{l}\text { - Directors of public and private services } \\
\text { - Heads of public and private services } \\
\text { - Administrative staff of the services } \\
\text { - Banking and microfinance and lawyers } \\
\text { - Agents of marriage and borough } \\
\text { - Administrative secretaries }\end{array}$} \\
\hline
\end{tabular}




\subsection{Duration of sitting posture over the course of a day in the subjects studied}

Table 2 shows the total time spent in a seated position. Indeed, this table shows that our subjects spend 13 hours of time in a sitting position during the day and about 8 hours of time asleep.

Table 2. Duration of sitting during the day

\begin{tabular}{ccc}
\hline & TASKS & $\begin{array}{c}\text { Average } \\
\text { durations }\end{array}$ \\
\hline Alarm clock & $\begin{array}{c}\text {-Follow the newspaper and the press review } \\
\text {-prepare business for service } \\
\text {-travel to the service: Sitting in the vehicle }\end{array}$ & 90 \\
\hline $\begin{array}{c}\text { Services during the } \\
\text { day }\end{array}$ & Perform his duties & 390 \\
\hline Pause & Breakfast & 45 \\
\hline After service & $\begin{array}{c}\text { Chat with colleagues } \\
\text { And others }\end{array}$ & \\
\hline & $\begin{array}{c}\text { Travel with your vehicle } \\
\text { Go see friends } \\
\text { Take a little refreshment } \\
\text { Game tables for some }\end{array}$ & 115 \\
\hline Back home & Travel with vehicle for re-entry \\
& Follow the newspaper, series or programs \\
Having dinner & 135 \\
& Review some documents of the day & \\
\hline
\end{tabular}

On average during the day, they spend 775 minutes or 13 hours in a sitting position during the day. This figure represents more than half of the length of an entire day.

3.3. Comparison of the change in the mean values of lumbar pain between the three groups during the experiment

\subsubsection{Evolution of mean pain values in the experimental groups}

The Figure 2 shows a progressive decrease in the mean lumbar pain value from the first session to the twelfth session in the two experimental groups. However, there was an increase in pain intensity in the control group. It gradually decreases from the seventh to the tenth session of the experiment.

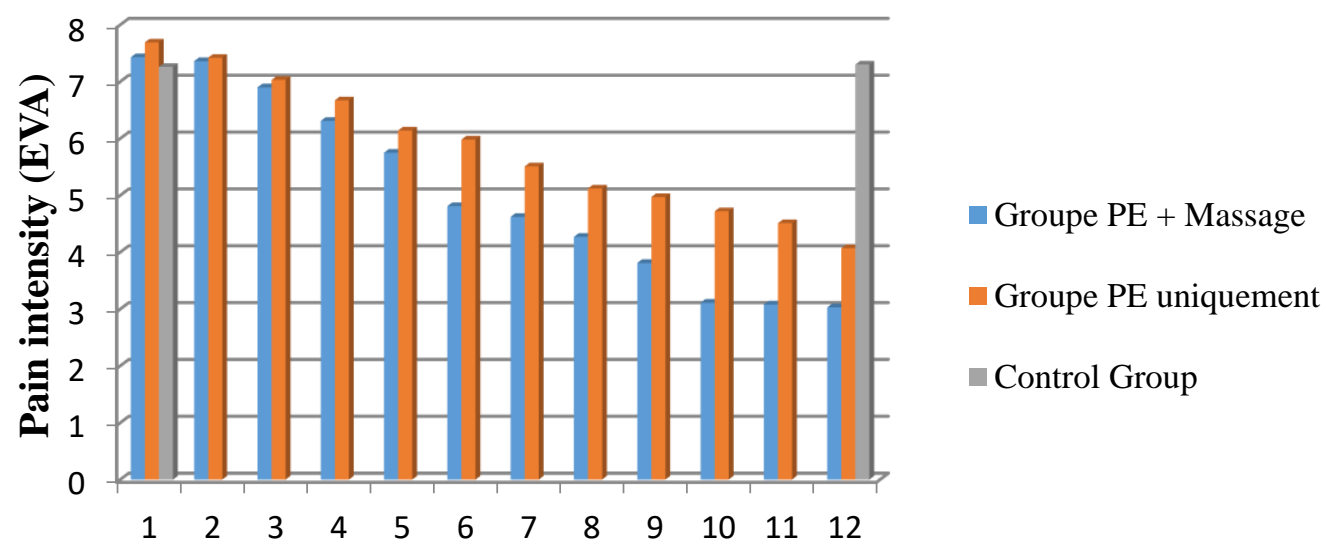

Evolution of mean pain values in the experimental groups

Figure 2. Evolution of mean pain values in the experimental groups 


\subsubsection{Comparison of pain intensity during sessions}

Associated sample Friedman 2nd order analysis of variance yielded $p$ less than 0.05 $(p=0.002)$. This shows that there is a significant difference between the level of pain taken per session at the experimental group level. Comparison of the pain intensity taken at the start of the experiment at each of the other sessions with the Wilcoxon rank test reveals that the difference is very significant from the sixth session because $p<0.01(p=0.003)$.

\subsubsection{Comparison of the mean values of lumbar pain during the study in the experi-} mental group and the control group

At the start of the study (Table 3), there was no significant difference between the mean back pain intensity between the three study groups $(p=0.39)$. A difference in pain intensity was observed in the PE only and PE + Massage groups at the end of the study. That of the PE + Massage group is more significant than that of the PE only group $(0.05<$ $0.02<0.00)$.

Table 3. Evolution of mean pain values during the study in the three experimental groups

\begin{tabular}{|c|c|c|c|c|c|c|c|c|c|c|c|c|c|}
\hline & No EVA & 1 & 2 & 3 & 4 & 5 & 6 & 7 & 8 & 9 & 10 & 11 & 12 \\
\hline Group PE & $M$ & 7,43 & 7,36 & 6,90 & 6,31 & 5,75 & 4,81 & 4,62 & 4,27 & 3,81 & 3,11 & 3,08 & 3,03 \\
\hline + massage & $\begin{array}{l}\text { Standard } \\
\text { deviation }\end{array}$ & 1,65 & 1,12 & 0,94 & 1,10 & 1,27 & 0,87 & 0,78 & 0,90 & 0,77 & 0,75 & 0,85 & 0,71 \\
\hline PE group & $M$ & 7,69 & 7,42 & 7,03 & 6,67 & 6,14 & 5,98 & 5,51 & 5,12 & 4,97 & 4,72 & 4,51 & 4,07 \\
\hline only & $\begin{array}{l}\text { Standard } \\
\text { deviation }\end{array}$ & 1,43 & 0,85 & 0,77 & 1,09 & 1,20 & 0,77 & 0,81 & 0,91 & 1,05 & 1,51 & 0,91 & 0,63 \\
\hline A group of & $M$ & 7,26 & - & - & - & - & - & - & - & - & - & & 7,31 \\
\hline witnesses & $\begin{array}{l}\text { Standard } \\
\text { deviation }\end{array}$ & 1,17 & - & - & - & - & - & - & - & - & - & - & 1,22 \\
\hline
\end{tabular}

\subsection{Comparison of functional disability of study sample subjects}

3.4.1. Evolution of the mean value of functional disability in the two PE groups during the study

Table 4 indicates that the mean values of functional disability decreased during the study in the two PE groups. In the PE + Massage group, the average rises at the start of the experimental period from $58.12 \pm 9.17$ to $17.55 \pm 5.29$ at the twelfth session.

Table 4. Evolution of the mean values of functional disability during the study

\begin{tabular}{cccc}
\hline & No ODI & $\begin{array}{c}\text { Beginning of experi- } \\
\text { mentation }\end{array}$ & End of Experimentation \\
\hline PE GROUP + & Mean & 58,12 & 17,55 \\
\cline { 2 - 4 } $\begin{array}{c}\text { Massage with } \\
\text { shea butter }\end{array}$ & $\begin{array}{c}\text { Standard } \\
\text { deviation }\end{array}$ & 09,17 & 05,29 \\
\hline PE GROUP only & Mean & 58,66 & 21,32 \\
\cline { 2 - 4 } & $\begin{array}{c}\text { Standard } \\
\text { deviation }\end{array}$ & 11,33 & 09,41 \\
\hline
\end{tabular}




\subsubsection{Comparison of functional disability between the PE + Massage group and the PE group only}

The comparison between the groups reveals that there is no significant difference between the mean values of functional disability between the two groups at the start of the experiment $(0.33>0.05)$. However, the comparison of the mean values at the end of the study shows a significant difference $(p=0.00)$.

\section{Discussion}

The main objective of this study was to evaluate the effect of the combination of an exercise program and massage with shea butter in the management of lower back pain and functional disability in sedentary civil servants. Inactive with 10 years of service and who spend almost all of their time in a seated position. We also wanted to measure the ability of our exercise prescription model to generate improvement in the physical characteristics assessed. In their review of the literature, Tulder [10], mentions that there is strong evidence for the effectiveness of exercise programs in the treatment of chronic low back pain. However, according to the author, no technique or method of exercise seems superior to another. We therefore decided to combine two methods of treating lumbar pain (an exercise program and massage with shea butter) in order to find out if our method could demonstrate better results than a conventional exercise program for the lumbar region. Pain and disability level serve as a benchmark for comparison between the three groups because they are not among the factors that influenced the choice of different exercises for our subjects. In addition, it is recognized that exercise programs have a positive influence on the pain level and the level of disability in people with lower back pain. Still in the same publication, Tulder [10] mentions that prescribing exercises for chronic low back pain would have a beneficial effect especially in the short term, which we decided to measure by developing an exercise program over a period of six weeks. Since our programming is based on the variation and progression of the various prescribed exercises, the program, in an experimental setting, could be extended over a longer period. A long-term approach might highlight even more the differences between the physical characteristics of the three groups.

We first evaluated the length of time during which the sedentary civil servants studied remained seated during the day. We have found that they spend more than half (13 hours) of the time in a sitting position. They remain seated at work, while driving their vehicle and at home ... In addition, these officials do not do any sporting activity that could allow them to relieve the spine. This increases the level of pain. In the literature [11-12], prolonged sitting posture and inactivity are risk factors for low back pain. The values obtained in the control group show that the intensity of the pain increased during the experimental period. These results suggest that these subjects need immediate management of this low back pain. The results of our study allow interesting conclusions about the effectiveness of exercise programs for the treatment of low back pain in sedentary public servants who spend almost all of their time in a sitting position. In fact, if we compare the evolution of back pain and functional disability in the groups that received the exercise program, we notice that the two groups experienced significant improvements compared to the control group. In the literature, several authors [13-15] have shown that there is strong evidence for the effectiveness of exercise therapy in the treatment of chronic low back pain. Isometric curls, mobility exercises, the McKenzie method, abdominal strengthening, the intensive dynamic back muscle training method and aerobic exercises are the methods frequently used in low back pain rehabilitation programs.

When comparing the level of pain and the level of disability in the two groups who received an exercise program, interesting differences are noted. Levels of pain and disability that were similar at the initial assessment differ from group to group at the final assessment. While the group of the combination of the exercise program and the massage 
with shea butter experienced a significant improvement in these two characteristics than that of the group of the exercise program only. The control group did not see any improvement between the first and sixth week. These results show that the combination of the exercise program and massage with shea butter would be effective in improving the level of pain and the level of functional disability of sedentary officials who spend most of their time sitting and suffering from lower back pain. It should be noted that to our knowledge there has been no study performed on the combination of the exercise program and massage with shea butter. And therefore, our study is the first to demonstrate the effectiveness of the combination of massage with shea butter and an exercise program in the management of lower back pain in subjects passing almost all of their time of day in a sitting position.

\section{Conclusion}

Sedentary officials suffering from low back pain associated with prolonged sitting posture of work and full-time driving of their vehicle, received three types of treatment according to the experimental group to which they are classified. Over a 6-week period, those subjects who received an exercise program experienced a significant decrease in their pain level and level of functional disability while subjects in the control group (no exercise program 'exercises) did not see any improvement. It should be noted that the reduction in lower back pain and disability is more significant in the group where massage with shea butter was added to the exercise program. These results show the effectiveness of physical activity and massage in treating lower back pain.

\section{Acknowledgments}

We extend our sincere thanks to Mr DOSSOU Assogba Nicolas, ZINSOU Honorine and to the heads of the Sport-Health-Service Center, CHUDO-PN, and the health centers that enabled the study to be carried out. Moreover, we thank all the subjects who accepted to participate in this study

\section{Annexes}

Table 5. Inter and intra group comparison of the pain mean values of our study sample

\begin{tabular}{ccc}
\hline & Statistical tests & P-value \\
\hline $\begin{array}{c}\text { Comparison of the intensity of pain at the start of the study be- } \\
\text { tween the two experimental groups }\end{array}$ & $\begin{array}{c}\text { Mann-Whitney U } \\
\text { test }\end{array}$ & 0,68 \\
\hline $\begin{array}{c}\text { Comparison of the intensity of pain at the start of the study be- } \\
\text { tween the PE group only and the control group }\end{array}$ & $\begin{array}{c}\text { Mann-Whitney U } \\
\text { test }\end{array}$ & 0,45 \\
\hline $\begin{array}{c}\text { Comparison of the intensity of pain at the start of the study be- } \\
\text { tween the PE + massage group and the control group }\end{array}$ & Mann-Whitney U \\
test & 0,71 \\
\hline $\begin{array}{c}\text { Comparison of pain intensity at the start and end of the study } \\
\text { in the control group }\end{array}$ & Test Wilcoxon \\
\hline $\begin{array}{c}\text { Comparison of pain intensity at the start and end of the study } \\
\text { in the PE + Massage group }\end{array}$ & Test Wilcoxon \\
\hline $\begin{array}{c}\text { Comparison of pain intensity at the start and end of the study } \\
\text { Comparison of the intensity of pain at the end of the study } \\
\text { between the two PE groups }\end{array}$ & $\begin{array}{c}\text { Test Wilcoxon } \\
\text { Mann-Whitney U } \\
\text { test }\end{array}$ \\
\hline
\end{tabular}

* Significant difference

**very significant difference 
Table 6. Inter and intra group comparison of the functional disability mean values of our study sample

\begin{tabular}{ccc}
\hline $\begin{array}{c}\text { Comparison of functional disability at the start } \\
\text { and that at the end of the study in the PE group } \\
\text { only }\end{array}$ & Statistical tests & P-value \\
\hline $\begin{array}{c}\text { Comparison of functional disability at the start } \\
\text { and that at the end of the study in the PE + Mas- } \\
\text { sage group with shea butter }\end{array}$ & $0,01^{*}$ \\
\hline $\begin{array}{c}\text { Comparison of functional disability assessed at } \\
\text { the start of the study between the PE group only } \\
\text { and the PE + Massage group }\end{array}$ & $\begin{array}{c}\text { Mann-Whitney U } \\
\text { test }\end{array}$ & $0,00^{* *}$ \\
\hline $\begin{array}{c}\text { Comparison of functional disability at the end of } \\
\text { the study between the PE group only and the PE + } \\
\text { group Massage with Shea butter }\end{array}$ & $\begin{array}{c}\text { Mann-Whitney U } \\
\text { test }\end{array}$ & $0,00^{* *}$ \\
\hline
\end{tabular}

*Significant difference

**very significant difference

\section{Conflicts Of Interest}

The authors declare no conflicts of interest.

\section{References}

[1] Airaksinen O, Brox JI, Cedraschi C, Hildebrandt J, Klaber-Moffett J, Kovacs F et al. European guidelines for the management of chronicnonspecificlow back pain. Eur Sect Cerv Spine Res Soc.2006;15 (2):192-300.

[2] BalagueF, MannionAF, PelliseF, Cedraschi C. Non-specific low back pain. Lancet. 2012 ;379(1):482-91.

[3] Kröner-Herwig Schmerzalsbiopsychosoziales B. Phänomen-eineEinführung, Schmerzpsychotherapie. Springer. 2011 :3-14.

[4] Marx G, Wirth D. Dynamisches Sitzen" im Vergleichzustatischen Sitzhaltungen - eineexperimentelle Studie Z. fürArbeitswiss.1996;50 (1):51-8

[5] Daian I, Van Ruiten AM, Visser A, Zubic S. Sensitive chair: a force sensing chair with multimodal real-time feedback via agent Proceedings of the 14th European Conference on Cognitive Ergonomics: Invent! Explore! London: ACM, United Kingdom; 2007. p. $163-6$

[6] Baumgartner D, Zemp R, List R, Stoop M, Naxera J, Elsig JP et al. The spinal curvature of three different sitting positions analysed in an open MRI scanner. Scientific WorldJ. 2012; (2012):184016.

[7] Andersson BJ, Ortengren R. Lumbar disc pressure and myoelectric back muscle activity during sitting. II. Studies on an office chair Scand. J rehabil Med.1974;6:115-21.

[8] Grandjean E, Hunting W. Ergonomics of posture - review of various problems of standing and sitting posture. ApplErgon.1977;8 :135-40.

[9] Krämer J. Biomechanische Veränderungenimlumbalen Bewegungssegment. Hippokrates-Verlag; 1973.

[10] Van TulderM W, KoesB W, BouterL M. Conservative Treatment of Acute and Chronic Nonspecific Low Back Pain. A Systematic Review of Randomized Controlled Trials of the Most Common Interventions. Spine (Phila Pa 1976).1997; 22(18):2128-56.

[11] Faas A, Van Eijk JTh M, Chavannes AW, Gubbels JW. A randomized trial of exercise therapy in patients with acutelow back pain. Spine. 1995; 20:941-7.

[12] Frost H, KlaberMoffet JA, Moser JS, Fairbank JCT. Randomised controlled trial for evaluation of fitnessprogramme for patients with chronic low back pain. BMJ 1995; 310:151-4.

[13] Abenhaim L, Rossignol M, Valat JP, Nordin M, Avouac B, Blotman F, et al. The rôle of activity in the therapeutic management of back pain. Report of the International Paris Task Force on Back Pain. Spine. 2000;25(4 Suppl):1S-33

[14] Arkuszewski Z. The efficacy of manual treatment in low back pain: A clinical trial. Manual Medicine.1986;2:68-71.

[15] Johanssen F, Remvig L, Kryger P. Exercises for chronic low back pain: A clinical trial. J Orthop Sports PhysTher. 1995; 22:52-9 